\title{
THE FRENCH REVOLUTION (1789 - 1799): NOTES FROM PSYCHIATRY
}

Psicointegral, Psychiatry unit, lima, Peru

\section{Objectives:}

To highlight some of the psychological and psychiatric phenomena that occurred during the French Revolution. Studies for Phillipe Pinel and letters of the historical period. Books of Davies about the french revolutions. Many hypotheses about mental health during the end of XVIII propose tertiary syphilis asresponsible for maniac and psychotic episodes among the followers and figures who led the beginning of French revolution.

\section{Methods:}

Review of literature, letters, the encyclopedias of the revolution and some clinical histories. This included a field visit to the "Cour de commerce" in october 2018.

Results: Many philosophes, like Voltaire and the E.J. Sieyes, promote the idea of division in states (1st, $2^{\text {nd }}$ and 3 rd state). It led a new phenomenon: belong to a group. This social phenomenon made it possible for the people to respond to small stimuli (the fear of closing the bridges near of Palais of Louvre). Also, the monarchy lost power. The taking of the Bastille was the most outstanding act. It was a symbolic fact to encourage for the people. In these moment, the predominance of collective hysteria dominated the acts, where personalities like Theorigne de Mericourt drives the people. She was a leader. Also, "L'ami du pueple", journal of J. P. Marat and the personality of G. J. Danton pushed the people.

\section{Conclusion:}

The social phenomenology had a major action in the direction of the actions that later named the great terror. Theres no concludent probes the syphilis was responsable for the actions in the french revolutions. The change in the course of thinking may be a reflect about of the social hysteria.
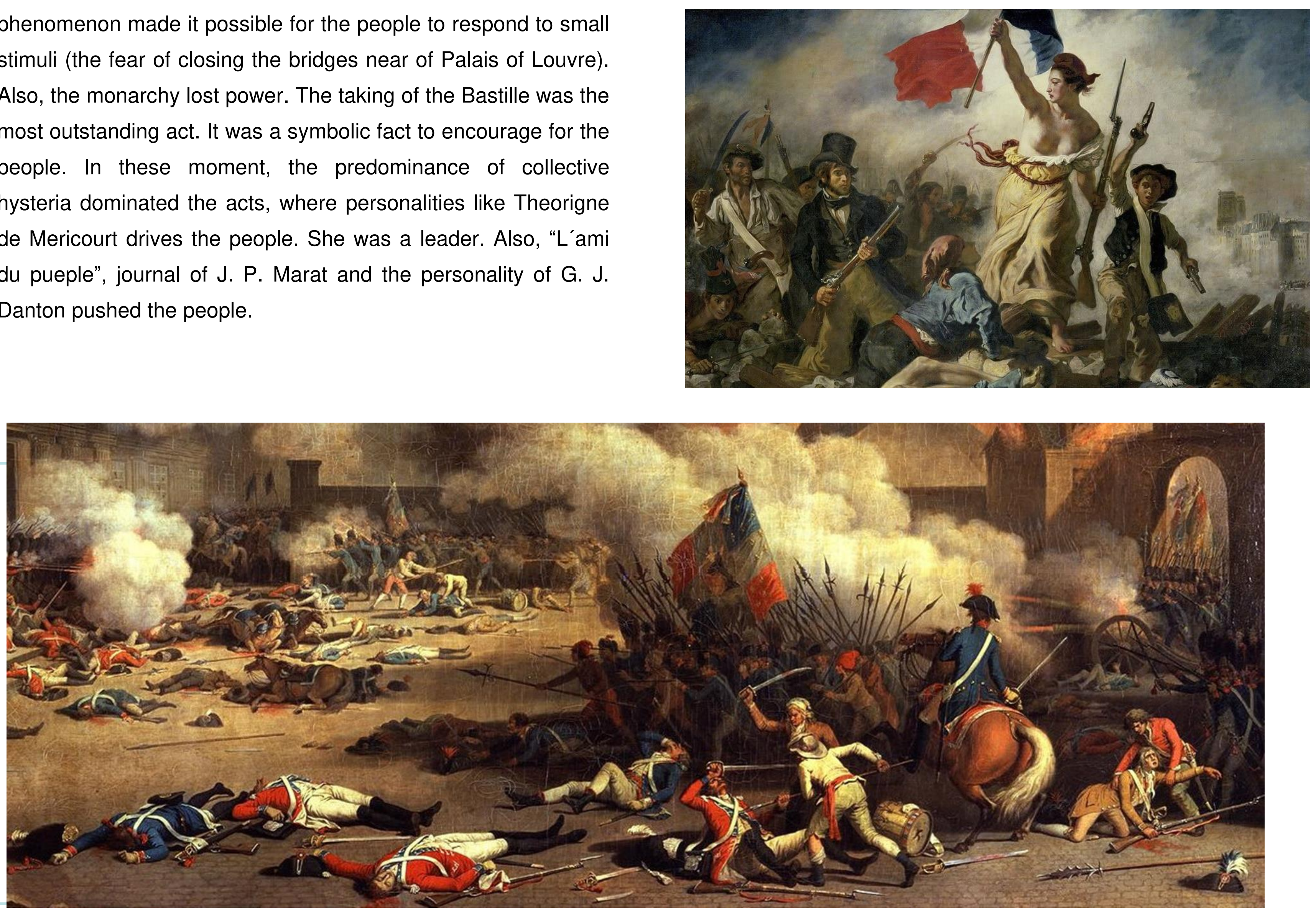